\title{
A LIBERDADE DE EXPRESSÃO E SEUS LIMITES NA INTERNET: UMA ANÁLISE A PARTIR DA PERSPECTIVA DA ORGANIZAÇÃO DOS ESTADOS AMERICANOS
}

FREEDOM OF EXPRESSION AND ITS LIMITS ON THE INTERNET: AN ANALYSIS FROM THE PERSPECTIVE OF THE ORGANIZATION OF AMERICAN STATES

Rosane Leal da Silva

Bárbara Eleonora Taschetto Bolzan

Paula Fabíola Cigana

\section{RESUMO}

O objetivo deste trabalho é investigar qual o entendimento da Organização dos Estados Americanos acerca do direito à liberdade de expressão e seus limites no contexto da Internet. Para tanto, foi utilizado o método de abordagem dedutivo e de procedimento monográfico, e as técnicas de pesquisa utilizadas foram revisão bibliográfica e análise documental. Conclui-se que o entendimento da Organização dos Estados Americanos é de que a liberdade de expressão é uma garantia fundamental nas sociedades democráticas, devendo ser amplamente defendida, ao passo que eventuais restrições devem ser cautelosamente analisadas e cumprir a determinados requisitos a fim de serem legítimas.

Palavras-chave: Direito à liberdade de expressão. Internet. Organização dos Estados Americanos. 


\section{ABSTRACT}

The purpose of this paper is to investigate the understanding of the Organization of American States about the right to freedom of expression and its limits in the context of the Internet. For that, the method of deductive approach and monographic procedure were used, and the research techniques used were bibliographic review and documentary analysis. It is concluded that the understanding of the Organization of American States is that freedom of expression is a fundamental guarantee in democratic societies and should be widely defended, while any restrictions must be carefully analyzed and meet certain requirements in order to be legitimate.

Keywords: Right to freedom of expression. Internet. Organization of American States.

\section{INTRODUÇÃo}

A liberdade de expressão é considerada um direito fundamental no atual ordenamento jurídico nacional. Após o triste período de ditadura, onde o direito de expressar ideias foi tolhido, o Brasil consagrou, no artigo 5ํㅡㄴ incisos IV e IX, da Constituição Federal, este tão importante direito.

Desta forma, pretende o ordenamento jurídico nacional possibilitar as múltiplas expressões, individuais e coletivas, no seio de uma sociedade tão plural como a brasileira. Como não poderia deixar de ser, atualmente, qualquer tentativa de reprimir ou censurar a livre manifestação de ideias é vista como grave afronta, e, especialmente, violação que deve ser prontamente combatida.

0 direito à liberdade de expressão também encontra respaldo na legislação internacional, em tratados e convenções, tanto no âmbito americano como mundial, revelando o reconhecimento e a importância deste direito pelos países e organizações internacionais.

Com o advento das novas tecnologias e popularização da internet, os fluxos de comunicação se expandiram, ampliaram os espaços de manifestação para além do campo físico, mas também no ambiente virtual. Este fato propiciou grandes avanços, possibilitando que os antes receptores, alçassem à condição de propagadores de conteúdo. 
Esse espaço amplo e heterogêneo, contudo, também trouxe implicações, algumas derivadas da própria forma de funcionamento da rede; outras, do uso que é feito pelos que a ela têm acesso. Dentre estes problemas, refere-se aqui à propagação de conteúdos que afrontam direitos de outros, exercício de liberdades que, por vezes, extrapolam os limites e atingem garantias e princípios tão caros ao ordenamento brasileiro. Nesta perspectiva, deve-se atentar para os abusos decorrentes do exercício do direito à liberdade de expressão.

Os tratados e convenções internacionais, bem como a Constituição Federal, dispõem sobre os limites à liberdade de expressão, corroborando a ideia de que nenhum direito fundamental é absoluto.

0 problema de pesquisa que este trabalho busca responder, portanto, é qual o entendimento e os limites do direito à liberdade de expressão, no contexto da Internet, no âmbito da América Latina, a partir da perspectiva da Organização dos Estados Americanos (OEA). Para tanto, serão analisados documentos elaborados pela referida organização, tanto no âmbito da Comissão Interamericana de Direitos Humanos (CIDH) como da Corte Interamericana de Direitos Humanos, especialmente no que toca a diretrizes para o uso apropriado da Internet, jurisprudências selecionadas e informes anuais sobre a liberdade de expressão.

A fim de responder o problema, utilizou-se o método de abordagem dedutivo, uma vez que foram analisados documentos em âmbito continental, seguido de sua aplicabilidade em campos mais específicos. Os procedimentos utilizados foram revisão bibliográfica e análise documental, posto que foram pesquisados diversos documentos atinentes ao problema proposto.

0 artigo divide-se em três seções, assim concebidas: em um primeiro momento, far-se-á um apanhado histórico acerca do desenvolvimento do direito à liberdade de expressão, bem como a sua definição, tanto doutrinária como legal, nos principais documentos internacionais e na Constituição Federal. Será analisada ainda a liberdade de expressão no contexto da Internet, discorrendo sobre os marcos teóricos atinentes e a forma de manifestação deste direito no âmbito virtual, assim como os principais entraves e/ou problemáticas daí advindas. 
Na segunda seção, por sua vez, será analisado o posicionamento latino americano, mais especificamente em relação ao Brasil, Uruguai e Argentina, em virtude da proximidade geográfica dos referidos países e por compartilharem aspectos relativos à formação histórico-política, sobre a temática, a partir de pesquisa bibliográfica de materiais diversos disponibilizados nos sítios eletrônicos da Organização dos Estados Americanos, tais como diretrizes e informes anuais, que indicam o posicionamento desta organização internacional no que se refere à liberdade de expressão e seus limites.

Por fim, na terceira seção, o estudo se voltará para a análise da temática sob a ótica dos Tribunais Nacionais da Argentina, do Uruguai e do Brasil, a partir de julgados referentes à temática contidos em documentos da Organização dos Estados Americanos.

\section{DIREITO À LIBERDADE DE EXPRESSÃO: DA CONSTRUÇÃO HISTÓRICA À MANIFESTAÇÃO ONLINE}

0 direito à liberdade de expressão, no contexto brasileiro, remonta a períodos de grande tristeza. A ditadura militar que acometeu o país e o medo de que este episódio volte a ocorrer são preocupações constantes. Este direito fundamental visa tutelar, nas palavras de Barroso (2007, p. 80) "o direito de externar ideias, opiniões, juízos de valor, em suma, qualquer manifestação do pensamento humano".

Nesta concepção, permitir que o indivíduo exponha suas opiniões é considerado primado básico do estado democrático de direito, e não se questiona seu valor. Esta liberdade é fundamental no desenvolvimento da personalidade, servindo também de fundamento para o exercício de outras liberdades (BARROSO, 2007). Pode-se dizer ainda que a liberdade antecede a própria noção de Estado, não sendo permitido a este, na concepção moderna de liberdade, interferir ou criar impedimentos ao indivíduo na prática de uma conduta (MEYER-PFLUG, 2009).

A amplitude desse direito encontra-se expressa na Constituição Federal, englobando a liberdade de consciência e de crença, a liberdade de culto, de informação, de reunião, de ensino, de comunicação e de 
imprensa. Portanto, este direito representa não somente a possibilidade de manifestação de ideias, mas também de participação social, de crer em algo sem sofrer represálias, de guiar-se de acordo com suas convicções íntimas, de obter informações que considere pertinente, de trocar ideias no seio da sociedade, dentre outros (MEYER-PFLUG, 2009).

A Lei 12.965/2014, denominada Marco Civil da Internet, é o texto normativo responsável por regulamentar o uso da Internet no Brasil. No entanto, embora o Marco Civil tenha trazido verdadeiros avanços sobre o uso da internet no país, muito se questiona acerca dos interesses escusos que circundam a elaboração do referido texto legal.

Dessa forma, questiona-se se o Marco Civil da Internet, ao tentar compatibilizar a liberdade de expressão com os direitos de personalidade, representaria, na verdade, um retrocesso, tendo privilegiado interesses econômicos em detrimento da proteção à dignidade da pessoa humana (PODESTA, 2015).

0 direito à liberdade de expressão é considerado fundamento e princípio do Marco Civil da Internet, conforme artigo $2^{\circ}$, caput, art. $3^{\circ}$, I, da Lei, o que denota a importância que lhe foi conferida pelo legislador. Do mesmo modo, a proteção aos direitos de personalidade encontra respaldo no art. $2^{\circ}$, II, art. $3^{\circ}$, II, e outros da supracitada lei.

Ademais, o art. 7ํㅡ, I, da Lei, prevê indenização por dano material ou moral decorrente de violação à intimidade e vida privada, sendo que os demais direitos de personalidade, como honra e reputação, são protegidos pelo art. 19, §3º , da Lei. Este parágrafo dispõe ser possível o ajuizamento de ação de ressarcimento de danos por conteúdos disponibilizados na Internet que atentem contra a honra, reputação, e outros direitos de personalidade (BRASIL, 2014).

Depreende-se da leitura do artigo 19, caput, da Lei 12.965/2014, que o legislador buscou isentar o provedor de conexão ${ }^{1}$ de qualquer responsabilidade por danos praticados por terceiros em ambiente virtual, ressalvando os casos em que, após ordem judicial, não forem adotadas as providências cabíveis para a remoção do conteúdo apontado como infringente (BRASIL, 2014). 
Perante a sociedade brasileira essa isenção se justificaria no fato de que os provedores prestariam serviço de relevante função social, promovendo a liberdade de expressão, acesso à educação, cultura.

Desse modo, inexiste atualmente, por parte do provedor, dever jurídico de realizar efetivo controle prévio dos conteúdos publicados pelo usuário, salvo nas hipóteses em que o dano viole os termos de uso e serviço ou se houver lei impondo a remoção do conteúdo, como ocorre no caso do art. 241-A, $1^{\circ}$, I I e II, e $\S 2^{\circ}$, do Estatuto da Criança e do Adolescente (PODESTA, 2015).

No que diz respeito à jurisprudência pátria, cumpre salientar que houve uma mudança de posicionamento a partir da Lei 12.965/2014. Antes da publicação deste texto legal, os provedores eram considerados responsáveis pelo conteúdo publicado caso, comunicados pelo interessado, não o tornassem indisponível. De outro lado, com a vigência do Marco Civil, a responsabilidade civil dos provedores de aplicações passou a depender do não cumprimento de ordem judicial determinando a remoção de conteúdo, tornando, portanto, o Poder Judiciário, instância competente a definir conteúdos como lícitos ou ilícitos (SOUZA, 2015).

No entendimento de Podesta (2015, p. 394), esse posicionamento adotado pelo legislador no art. 19, ainda que de forma "mascarada", denota a influência da preferred position norte-americana no texto brasileiro, na medida em que "leva em conta um lugar de preferência em relação à liberdade de expressão caso haja sua colisão com outros direitos fundamentais ou da personalidade".

A exigência de postulação prévia em juízo para que se possam proteger os direitos de personalidades traz consequências gravosas, na medida em que as informações circulam de forma veloz e ilimitada no âmbito da Internet. A cada segundo que se passa sem que se proceda à retirada da informação do ambiente virtual, maiores são os danos à imagem e honra da pessoa lesada.

Nesse sentido, o supracitado autor (2015) traz como sugestão a possibilidade de os provedores de serviço implantarem uma central com o intuito de analisar reclamações de usuários previamente, como método alternativo de resolução dos conflitos ${ }^{2}$. No entanto, tal sugestão é fonte de severas críticas e desconfianças por parte de estudiosos da área, na 
medida em que seria capaz de legitimar diversos discursos e práticas atentatórias à liberdade de expressão.

Cumpre frisar que, em julgamento realizado pela Suprema Corte Argentina, em 28 de outubro de 2014 - onde se discutia a responsabilização de provedores de internet pela exibição de fotos não autorizadas e direcionamento a sites de conteúdo adulto - debateu-se a questão da imposição da filtragem de conteúdos por meio de sites em contraposição ao direito à liberdade de expressão. Na ocasião, firmouse posicionamento no sentido de que a mera notificação privada não é suficiente para acarretar a responsabilidade do provedor, tendo em vista que se "[...] questiona os efeitos de se criar um sistema em que qualquer pessoa poderia notificar o provedor e com isso ver o conteúdo removido". (SOUZA, 2015, p. 400).

Dessa forma, é imperioso que se enfrente a questão da responsabilidade civil do provedor de internet de forma cuidadosa, tendo em vista que "Um sistema de responsabilidade objetiva, por exemplo, ao tornar o provedor de aplicações diretamente responsável pelo conteúdo exibido, incentiva o dever ativo de monitoramento e exclusão de conteúdos potencialmente controvertidos" (SOUZA, 2015, p. 398).

Farias (2001) chama a atenção para as duas concepções que podem ser compreendidas a partir da liberdade de expressão: a perspectiva subjetiva e a perspectiva objetiva. Em relação à primeira, refere englobar teorias que entendem a liberdade de expressão como um valor indispensável para a proteção da dignidade da pessoa humana e o desenvolvimento da personalidade. Nesta seara, esta concepção é associada, inicialmente, ao caráter liberal, preconizando a autonomia e autodeterminação das pessoas na busca da verdade.

A segunda concepção, de caráter objetivo, reúne teorias que entendem a liberdade de expressão como instrumento em prol do regime democrático, uma vez que propicia a participação dos cidadãos no debate público. Destaca-se, como expoentes desta perspectiva, James Madison e o juiz norte americano Louis Brandeis, sendo que ambos concebem a liberdade de expressão como "algo essencial para a consecução do autogoverno popular" (FARIAS, 2001, p. 59), e Alexander Meiklejohn³ um dos mais importantes defensores da concepção objetiva. 
Portanto, associa-se o direito à liberdade de expressão ao regime democrático de direito, sendo este direito o corolário da democracia. Para Almeida (2012, p. 9), o direito à liberdade de expressão chega "a ter o status de direito quasi-absoluto em alguns ordenamentos jurídicos pelo mundo".

Como direito fundamental, sua proteção é ampla, e esse direito é tutelado em suas diversas formas, seja escrita, falada ou através da Internet. Ademais, observa-se que se configura como direito inerente ao ser humano, pois através de seu exercício este constitui formas de interação e participação na sociedade, podendo integrar ativamente uma comunidade (MEYER-PFLUG; LEITE, 2015).

Em âmbito internacional este direito também é amplamente protegido. Diversos documentos internacionais ${ }^{4}$ asseguram o direito à liberdade de expressão e o reconhecem como fundamental para o desenvolvimento das sociedades democráticas. No âmbito de produção americano, os mais importantes diplomas são a Convenção Americana sobre Direitos Humanos (Pacto de San José da Costa Rica), ratificado pelo Brasil em setembro de 1992, a qual prevê, em seu artigo 13, o direito de todos à liberdade de pensamento e de expressão, incluídas aí a liberdade de buscar, receber e difundir informações e ideias de toda natureza, por qualquer meio, e a Declaração Americana dos Direitos e Deveres do Homem, do ano de 1948, que prevê, no artigo IV, a proteção a este direito.

Consoante se extrai dos diplomas acima referidos, a proteção à liberdade de expressão é abrangente, incluindo variadas formas de expressão, bem como diversos meios pelos quais este direito pode ser exercido, como através da Internet.

A cibernética ${ }^{5}$ tem origem na $2^{\text {a }}$ Guerra Mundial, encontrando seu ápice durante o período da Guerra Fria com o desenvolvimento de um calculador analógico. Mais tarde, sob o ideal do modelo econômico neoliberal das democracias ocidentais desenvolveu-se o ciberespaço, instrumento de aceleração social.

Essa aceleração social revelada no âmbito Internet provocou uma verdadeira transformação do estatuto do sujeito e propiciou a criação de uma nova individualidade, agora coletivizada e dessubjetivada. Por essa razão, entende-se que a aproximação entre homem e máquina instituiu 
uma nova forma de totalitarismo, o qual ao mesmo tempo em que exerce pressão sobre desejos e ações dos sujeitos, torna-se inescapável e onipresente a todos os aspectos da vida social (SALDANHA, 2013).

Nesse contexto, indaga-se se o uso das TIC $^{6}$ como instrumento de liberdade de expressão caracteriza uma forma de liberdade perfeita ou de controle perfeito ${ }^{7}$. Ao que parece, essas duas expressões não podem ser dissociadas na medida em que ao mesmo tempo em que o ciberespaço propicia o exercício de ampla liberdade de expressão, fomentando o debate e compartilhamento de temas que outrora não eram alcançados pela população, também acaba por permitir o controle geral e ilimitado por quem é dotado de poder político, econômico e expertise cibernética para tanto (SALDANHA, 2013).

Em outras palavras, a liberdade de comunicação foi concomitantemente expandida e reduzida. Mostrou-se expandida no que diz respeito ao número de pessoas em comunicação em curto espaço de tempo, ao passo que foi reduzida em relação à privacidade de nossas comunicações, que atualmente podem ser armazenadas e utilizadas de diversas formas contra o usuário (ASSANGE, 2013).

Os indivíduos contribuem de forma voluntária para a perpetuação da vigilância silenciosa no ciberespaço ao utilizarem de sites como Google, Yahoo, Facebook, entre outros. As redes sociais, em especial, incitam o desejo de compartilhamento da vida íntima entre as pessoas como forma de reconhecimento perante o outro, fenômeno esse que é chamado de "extimidade". Assim sendo, essas grandes transnacionais da comunicação e informação permitem o armazenamento e manipulação de dados pessoais de seus usuários (SALDANHA, 2013).

A facilitação da liberdade de expressão nas redes surge como verdadeiro paradoxo em relação à banalização da mesma liberdade de expressão. Esta banalização da liberdade de expressão no ambiente da Internet "está associada à ideia hoje corrente de que qualquer restrição à livre-circulação das informações e à liberdade de expressão é socialmente nefasta" (SALDANHA, 2013, p. 202).

Assim sendo, a própria banalização da liberdade de expressão evidenciada em discursos de ódio, terror, entre outros, acaba por 
enfraquecer o viés democrático que a circunda, passando a servir até mesmo como justificativa à vigilância estatal sobre o ciberespaço.

A busca por limites à liberdade de expressão no âmbito da internet tem-se mostrado uma latente necessidade do próprio regime democrático. No entanto, essas limitações e regulações ainda se mostram incipientes e territorializadas (SALDANHA, 2013).

Por essa razão, mostra-se imperiosa uma análise detalhada acerca das diretrizes e limitações à liberdade de expressão em âmbito nacional e latino-americano, o que será abordado no capítulo seguinte.

\section{A LIBERDADE DE EXPRESSÃO NA PERSPECTIVA LATINO AMERICANA: DIRETRIZES E LIMITAÇÕES}

Feitas as considerações iniciais sobre o direito à liberdade de expressão e sua manifestação na Internet em um contexto mais amplo, passa-se a análise do posicionamento deste direito em âmbito mais restrito. Inicia-se referindo sobre o entendimento da temática na América Latina, sob a ótica da Organização dos Estados Americanos, passando-se a análise do tema mais especificamente no Uruguai e na Argentina.

A história latino americana é marcada por ditaduras sangrentas, cujos resquícios ainda são muito presentes em alguns países, especialmente em razão do não esclarecimento de atos cometidos naquele período, não obstante o processo de redemocratização e o advento de Constituições democraticamente instituídas.

Com base nisso, faz-se imperioso analisar o tratamento dado à liberdade de expressão neste âmbito, com base no entendimento da Organização dos Estados Americanos, e mais especificamente, da Comissão Interamericana de Direitos Humanos.

A Organização dos Estados Americanos foi criada em 1948, quando da assinatura da sua Carta, em Bogotá, na Colômbia, a qual entrou em vigor em 1951. Atualmente compreende 35 países independentes do continente americano, tendo como objetivos lograr aos Estados-membros "uma ordem de paz e de justiça, fomentar sua solidariedade, robustecer 
sua colaboração e defender sua soberania, integridade territorial e sua independência" ${ }^{8 "}$ (OEA, 1948, tradução nossa).

A Comissão Interamericana de Direitos Humanos (CIDH) é um dos órgãos principais e autônomos da OEA, tendo sido criada em 1959 e, juntamente com a Corte, compõe o denominado Sistema Interamericano de proteção dos Direitos Humanos (SIDH). De acordo com informações contidas no sítio oficial da OEA, a Comissão Interamericana de Direitos Humanos tem como primado "a promoção e proteção dos direitos humanos no continente americano ${ }^{9 ”}$ (OEA, 2017, tradução nossa).

Feito este pequeno introito histórico, passa-se a análise do entendimento da América Latina, a partir dos documentos disponibilizados no endereço eletrônico da OEA, sobre o direito à liberdade de expressão na Internet, e as hipóteses nas quais a limitação a tal direito é justificada.

O documento intitulado "Estándares para una Internet libre, abierta e incluyente", da Relatoria Especial para a Liberdade de Expressão ${ }^{10}$, publicado em março de 2017, reconhece que a maior contribuição da Internet para o direito à liberdade de expressão é que esta ampliou a capacidade das pessoas de receberem, buscarem e difundirem informações, o que "permite a criação em colaboração e o intercâmbio de conteúdos - é um âmbito onde qualquer um pode ser autor e qualquer um pode publicar ${ }^{11 "}$ (CIDH, 2017, p. 37, tradução nossa).

Ainda segundo o documento supracitado, a Internet se revela como uma força a serviço da democratização, que opera

[...] transformando o direito à liberdade de expressão mediante a criação de novas capacidades para criar e editar conteúdos (através de fronteiras físicas), frequentemente sem passar pelo controle da censura, o que gera novas possibilidades para a realização do potencial; novas capacidades de organização e mobilização (que respaldam em grande medida outros direitos, como o direito a liberdade de associação); e novas possibilidades para inovas e gerar desenvolvimento econômico (que sustentam os direitos sociais e econômicos) ${ }^{12}$ (CIDH, 2017, p. 37, tradução nossa).

Este entendimento é renovado em outros documentos elaborados pela Relatoria, corroborando a noção de que a Internet é vista como uma importante ferramenta na busca pela efetividade do direito à liberdade de 
expressão. De acordo com o Informe Anual do ano de 2013, da Relatoria Especial para a Liberdade de Expressão, é reconhecido que o direito à liberdade de expressão, "encontra na Internet um instrumento único para estender, incrementalmente, seu enorme potencial em amplos setores da população ${ }^{13 "}$ (CIDH, 2013a, p. 495, tradução nossa).

O Informe reconhece o espaço digital como meio de promoção do intercâmbio de informações e opiniões, e que a partir desta perspectiva, a configuração e arquitetura da rede são pontos chave. Por isso, qualquer regulação que seja produzida deve resultar, conforme entendimento da Relatoria, do diálogo de todos os atores e deve manter as características básicas originalmente instituídas, a fim de que permita a potencialidade democratizadora da Internet (CIDH, 2013a).

Como forma de promover e, sobretudo, permitir a liberdade de expressão online, o entendimento da CIDH é pautado na promoção de alguns princípios, dentre eles, a neutralidade da rede. Segundo o Informe anual de 2013,

0 que este princípio refere é que a liberdade de acesso e de escolha para os usuários para usar, enviar, receber ou oferecer qualquer conteúdo, aplicativos ou serviços jurídicos através da Internet não está condicionada, dirigido ou restringido por meio de bloqueio, filtragem, ou interferência. É uma condição necessária para o exercício da liberdade de expressão na Internet, nos termos do artigo 13 da Convenção Americana ${ }^{14}$ [...] (CIDH, 2013a, p. 500, tradução nossa).

Outro ponto de destaque é a necessidade de promoção do acesso à Internet para que seja efetivado o direito à liberdade de expressão. A jurisprudência interamericana consolidou o entendimento de que a liberdade de expressão se consubstancia como um direito de dupla dimensão: uma individual e outra coletiva ou social. Isto traz como consequência que este direito é tanto um instrumento para a troca de informações e ideias entre as pessoas, como para a comunicação massiva entre os seres humanos, o que implica tanto o direito de comunicar aos outros o seu ponto de vista como o direito de todos de receberem informações, opiniões, etc., sem qualquer tipo de interferência que as obstaculize ou as distorça (CIDH, 2013a). 
A partir destas premissas, para a consolidação de uma sociedade plural e igualitária, onde todos tenham espaços de fala, é imperiosa a ampliação do acesso à internet. A fim de alcançar tal propósito, o Informe (CIDH, 2013a) propõe três pontos-chave: 1) medidas de inclusão que ponham fim ao "fosso digital"; 2) planos que assegurem que a infraestrutura e os serviços garantam, progressivamente, o acesso universal ${ }^{15}$; e 3) medidas que proíbam o bloqueio e a limitação ao acesso à Internet.

Salienta-se que a efetiva participação social por meio da rede pressupõe uma abertura da rede, que é atingida por meio do acesso igualitário a esta. Este acesso incrementa o pluralismo informativo e a diversidade cultural, mas pressupõe a participação das minorias linguísticas. A este respeito, o Informe (CIDH, 2013a, p. 507) é pontual, ao estabelecer que "é necessário que se adotem as medidas tendentes a reduzir os obstáculos linguísticos para garantir que as distintas culturas possam se expressar e acessar a Internet ${ }^{16 "}$ (tradução nossa).

Importante referir ainda a estreita relação entre o direito à liberdade de expressão e a democracia, na concepção da CIDH. Em razão do passado histórico dos países americanos, especialmente no âmbito da América Latina, o entendimento expresso no Marco Jurídico Interamericano sobre o Direito à liberdade de expressão (CIDH, 2010, p. 3) é no sentido de que o pleno exercício de tal garantia

[...] é condição indispensável para a consolidação, o funcionamento e a preservação dos regimes democráticos. A formação de uma opinião pública informada e consciente de seus direitos, o controle cidadão sobre a gestão pública e a exigência de responsabilidade dos funcionários estatais, não seria possível se esse direito não fosse garantido ${ }^{17}$ (tradução nossa).

Salienta-se que a formação da opinião pública informada, como meio de participação social na rede pressupõe a capacitação dos seus usuários, para que possam fazer uso autônomo, independente e responsável das tecnologias digitais. Neste sentido, a Relatoria entende pela imprescindibilidade de promoção, por parte das autoridades, da "alfabetização digital", já que o acesso pleno às TICs mantém estreita 
relação com a capacidade de fazer uso efetivo destas ferramentas (CIDH, 2013b).

Feitas essas considerações acerca das dimensões, conceito e abrangência do direito à liberdade de expressão, com especial ênfase para o âmbito da Internet, passa-se a análise das hipóteses de limitação deste direito sob a ótica da Organização dos Estados Americanos.

De antemão, refere-se que, assim como as demais garantias fundamentais, o direito à liberdade de expressão não é absoluto. 0 alcance desse direito encontra-se previsto na Constituição Federal, a qual veda o anonimato e garante o direito de resposta, conforme artigo $5^{\circ}$, inciso $\mathrm{V}$, bem como protege o direito à imagem, à honra, à intimidade e à privacidade. Farias (2001) refere que as restrições podem ser tanto expressas, nas hipóteses em que a Constituição as impõe de forma direta, quanto tácitas, quando a Carta Constitucional abona que o legislador ou o judiciário as formulem.

0 autor destaca ainda que a temática das restrições à liberdade de expressão pode ser vista sob duas tradições jurídicas diversas. A primeira delas, que surgiu com a Declaração dos Direitos do Homem e do Cidadão "caracteriza-se pelo fato de configurar a liberdade de expressão e comunicação e, logo em seguida, predeterminar que a lei estabelecerá as restrições para reprimir os abusos resultantes da utilização daquela liberdade" (FARIAS, 2001, p. 222). Já a segunda concepção tem como fundamento a Primeira Emenda à Constituição dos Estados Unidos da América, e "distingue-se pela configuração da aludida liberdade sem previsão legal de restrição" (FARIAS, 2001, p. 222).

Os documentos internacionais referidos neste trabalho também preveem as hipóteses excluídas do manto da liberdade de expressão ${ }^{18}$. Neste sentido, o parágrafo 2 do artigo 13 da Convenção Americana de Direitos Humanos (Pacto de San José da Costa Rica), expressa a possibilidade de responsabilidades ulteriores decorrentes do exercício da liberdade de expressão, as quais também devem estar previstas em lei e ter como propósito assegurar o respeito às demais pessoas ou a proteção da segurança nacional, da ordem pública ou da moral públicas. 0 parágrafo 5 refere ainda que "a lei deve proibir toda propaganda a favor da guerra, bem como toda apologia ao ódio nacional, racial ou religioso 
que constitua incitamento à discriminação, à hostilidade, ao crime ou à violência" (BRASIL, 1992).

Conforme exposto, os tratados internacionais trazem a possibilidade de restrição ao direito à liberdade de expressão, mas sempre apontando que eventuais restrições devem ser previstas em lei e só se dão em casos específicos, a fim de evitar limitações que importem em restrição ilegal deste direito. A esse respeito, faz-se relevante a distinção feita por Farias (2001) entre restrição e censura. 0 autor explica que a primeira tem fundamento constitucional, relacionada a uma medida legislativa ou judicial que almeje a harmonia da liberdade de expressão com os demais direitos, enquanto que a segunda é vedada, repelida pela Carta Constitucional, justamente porque aniquila o direito à liberdade de expressão, ligada a atos do Poder Executivo e aos detentores do poder político.

No que concerne aos documentos objeto de análise do presente trabalho, faz-se pertinente referir o disposto no Marco Jurídico Interamericano sobre o direito à Liberdade de Expressão. Este documento prevê que "o exercício da liberdade de expressão implica deveres e responsabilidades para quem se expressa. 0 dever básico que daí deriva é o de não violar os direitos dos demais ao exercer essa liberdade fundamental ${ }^{19 "}$ (CIDH, 2010, p. 6, tradução nossa).

O que o Marco Jurídico (CIDH, 2010) aponta é que, não obstante a presunção de proteção $a b$ initio das manifestações, alguns discursos são excluídos do manto da liberdade de expressão. Dentre eles, menciona-se a propaganda de guerra e a apologia ao ódio que constitua incitação à violência, a incitação direta e pública ao genocídio e a pornografia infantil.

Ainda de acordo com o Marco Jurídico, a Convenção Interamericana estipulou algumas condições que as limitações devem cumprir para que sejam consideradas legítimas. Parte-se de uma regra geral, que preconiza que as limitações à liberdade de expressão devem se coadunar com as exigências de uma sociedade democrática. Ou seja, como mínimo, se exige que qualquer restrição à liberdade de expressão não colida com os valores democráticos pelos quais se pauta uma sociedade.

Após a análise deste primeiro critério, deve-se atentar para o chamado "test tripartito" (CIDH, 2010, p. 24), onde são elencadas três etapas que devem ser superadas para que uma restrição à liberdade 
de expressão possa ser legitimada. Neste sentido, o entendimento consolidado pela jurisprudência interamericana é de que:

(1) a limitação deve ter sido definida de forma precisa e clara através de lei formal e material, (2) a limitação deve estar orientada para a realização de objetivos imperiosos autorizados pela Convenção Americana, e (3) a limitação deve ser necessária em uma sociedade democrática para a realização dos fins imperiosos que se buscam; estritamente proporcional a finalidade perseguida; e idônea para alcançar o objetivo imperioso que se pretende ${ }^{20}$ (CIDH, 2010, p. 24, tradução nossa).

0 atendimento a estes requisitos é imprescindível para que se considere uma restrição legítima, sendo que cabe a autoridade que impuser a restrição a comprovação de que tais condições foram satisfeitas. Frisa-se também que é necessário o cumprimento de todas as condições simultaneamente.

O Marco Jurídico (CIDH, 2010) ainda contempla os tipos de limitação incompatíveis com o que dispõe o artigo 13 da Convenção Americana. Em suma, as limitações não podem equivaler a censura, não podem ser discriminatórias ou produzir efeitos discriminatórios, não podem ser impostas por meios indiretos proibidos pela Convenção e devem ser excepcionais.

A despeito destas observações em relação às limitações ao direito à liberdade de expressão, é importante mencionar sobre as peculiaridades em matéria de restrição no âmbito da Internet. Como já referido neste trabalho, o direito à liberdade de expressão encontra na Internet um forte aliado, representando um amplo espaço para manifestação de ideias, de opiniões e acesso a informações. Como consequência, entende-se que a restrição ao direito à liberdade de expressão deve ser analisada sob uma perspectiva sistêmica e com base na proporcionalidade, já que

[...] uma determinada medida restritiva pode parecer leve se estudada somente da perspectiva da pessoa afetada. Porém, a mesma medida pode ter um impacto realmente devastador no funcionamento geral da Internet e, em consequência, no direito à liberdade de expressão de todo o conjunto de usuários ${ }^{21}$ (CIDH, 2013b, p. 27, tradução nossa). 
São referidos requisitos mínimos para que seja admissível a restrição ao direito à liberdade de expressão na Internet, que podem ser compilados em cinco, assim definidos pela CIDH: "(1) previsão legal; (2) busca de uma finalidade imperativa; (3) necessidade, idoneidade e proporcionalidade da medida para alcançar a finalidade perseguida; (4) garantias judiciais; e (5) cumprimento do devido processo, incluindo as notificações ao usuário 22" (CIDH, 2013b, p. 28, tradução nossa).

0 primeiro ponto diz respeito a um critério que deve ser observado tanto no âmbito da internet como fora dela. Preceitua que as restrições devem ser previstas em lei, no sentido formal e material, e que tais leis sejam claras e objetivas. A ambiguidade ou imprecisão de uma lei representa, na percepção da CIDH, grave afronta à liberdade de expressão (CIDH, 2013b).

Quanto à finalidade imperativa das restrições, significa dizer que os motivos que ensejaram a definição destas devem tencionar assegurar objetivos democraticamente instituídos, como a proteção de direitos dos demais, a ordem pública, dentre outros. Este ponto se liga com o terceiro, o qual prevê que a limitação deve ser proporcional e idônea à finalidade almejada, evitando, desta forma, a imposição de limitações que não guardam coerência com o objetivo da restrição (CIDH, 2013b).

A quarta condição se refere ao respeito às garantias relativas ao devido processo e a reserva judicial, nos termos expressos nos artigos 8 e 25 da Convenção Americana. Por fim, a quinta condição, a qual é proveniente do caráter global da Internet, preceitua que

[...] a jurisdição das causas vinculadas com expressões na Internet deveria corresponder exclusivamente aos Estados com os quais tais causas mantenham relação mais próxima, normalmente em razão do autor residir neste Estado, a expressão ter sido publicada a partir dali ou esta se dirigir especificamente a um público localizado no Estado em questão. Os particulares somente deveriam poder ajuizar ações na jurisdição na qual possam demonstrar ter sofrido um prejuízo substancial, de maneira que se previna o que se conhece por "turismo da difamação" (fórum shopping ${ }^{23}$ ) (CIDH, 2013b, p. 31-32, tradução nossa).

Do exposto, percebe-se que a Comissão entende que o direito à liberdade de expressão tem grande relevância, e que eventuais restrições 
devem passar pelo crivo de alguns requisitos, sendo fundamentados e adequados para o fim proposto. Tal posicionamento é compreensível, tendo em vista o contexto histórico atravessado pelos países latino americanos, mas não se pode deixar de considerar que o potencial da Internet, fortemente destacado pela CIDH como ferramenta à serviço da democracia, atualmente é utilizado para a propagação de discursos não abrangidos pela liberdade de expressão, e que em virtude das capacidades da Internet, se alastram rapidamente, ferindo direitos fundamentais de outras pessoas ou grupo de pessoas.

Muito embora a Comissão entenda que nos casos de divulgação de conteúdos explicitamente ilícitos e não resguardados pelo direito à liberdade de expressão seja admissível “a adoção de medidas obrigatórias de bloqueio e filtragem de conteúdos específicos ${ }^{24 "}$ (CIDH, 2013b, p. 40, tradução nossa), é sabido que a este ponto os conteúdos ilícitos já causaram danos e atingiram um número indefinido de vítimas, sem mencionar a possibilidade de serem hospedados em outros endereços eletrônicos.

Compreendido o panorama geral da liberdade de expressão em âmbito latino-americano, passa-se à análise dos regramentos legais internos e entendimentos jurisprudenciais de alguns estados nacionais, como Argentina, Brasil e Uruguai, abarcando suas principais diretrizes e limitações.

\section{A LIBERDADE DE EXPRESSÃO NA JURISPRUDÊNCIA ARGENTINA, URUGUAIA E BRASILEIRA}

Na Constituição Argentina ${ }^{25}$, a liberdade de expressão encontra-se inserta no artigo $14^{26}$, dispositivo esse que trata mais especificamente da liberdade de imprensa, assegurando a publicação de ideias sem censura prévia.

No entanto, é de se salientar que somente em 02 de agosto de 2016 o Presidente argentino Maurício Macri aderiu à Declaração de Chapultepec sobre a Defesa da Liberdade de Expressão, que fora celebrada em 1994, no México (CLARÍN, 2016). Esse documento é de suma importância, na 
medida em que prevê uma série de princípios relativos à liberdade de expressão, adentrando de forma especial na temática da liberdade de imprensa enquanto verdadeiro mecanismo de exercício democrático.

A respeito da liberdade de expressão no âmbito da Internet foi promulgada a Lei 26.032/2005, cujo art. $1^{\circ}$ p prevê que "A busca, recepção e difusão de informação e ideias de toda natureza, através do serviço da internet, se considera compreendida dentro da garantia constitucional que ampara a liberdade de expressão" (ARGENTINA, 2005, tradução nossa).

De igual forma, a liberdade de expressão também se encontra expressamente prevista na Constituição Uruguaia, abarcando a garantia de liberdade de comunicação de pensamentos escritos de forma privada ou publicados na imprensa, ou qualquer outra forma de divulgação, sem existência de prévia censura. Nesse sentido, percebe-se, de pronto, que a Carta uruguaia ampliou a noção de liberdade de expressão em relação à Constituição argentina, na medida em que aquela abrange qualquer forma de comunicação e divulgação de opinião, ao contrário desta, que trata somente da publicação de ideias pela imprensa, sem censura prévia.

Artigo 29.- É inteiramente livre em toda matéria a comunicação de pensamentos por palavras, escritos privados ou publicados pela imprensa, ou qualquer outra forma de divulgação, sem necessidade de prévia censura; restando responsável o autor, e em seu caso, o impressor ou emissor, de acordo com a lei, pelos abusos que cometeram ${ }^{27}$ (URUGUAY, 1967, tradução nossa).

Ainda em relação ao exercício da liberdade de expressão no Estado uruguaio, foi promulgada a Lei 19.307/2014 a fim de tratar da regulação da prestação de serviços de comunicação audiovisual. A referida lei traz, em seu bojo, diversos dispositivos atinentes ao exercício da liberdade de expressão, o qual, segundo o art. 7ํㅡㄹ corresponde a um dos princípios basilares da mencionada normativa. Nessa senda, o art. 22 da Lei estabelece que "Toda pessoa tem direito à liberdade de expressão. Este direito compreende a liberdade de buscar, receber e difundir informações e ideias. ${ }^{28}$ [...]" (URUGUAY, 2014, tradução nossa).

Cumpre salientar que um regramento legal uruguaio que encontra certa similitude com dispositivos do Marco Civil da Internet Brasileiro 
é a Lei no 18.331/2008, tendo em vista que trata da proteção de dados pessoais no país, incluindo as bases de dados processadas de forma eletrônica ${ }^{29}$.

Artigo 20. Dados relativos às telecomunicações. - As operadoras que explorem redes públicas ou que prestem serviços de comunicações eletrônicas disponíveis ao público deverão garantir, no exercício de sua atividade, a proteção dos dados pessoais, conforme a presente lei. Também, deverão adotar as medidas técnicas e de gestão adequadas para preservar a seguridade na exploração da sua rede ou na prestação de seus serviços, com o fim de garantir os níveis de proteção dos dados pessoais que sejam exigidos pelo regulamento de execução desta lei em tal matéria. Caso exista um risco particular de violação da segurança da rede pública de comunicações eletrônicas, o operador que explore dita rede ou preste o serviço de comunicações eletrônicas informará aos assinantes sobre tal risco e sobre as medidas a serem adotadas ${ }^{30}$ [...] (URUGUAY, 2014, tradução nossa).

No que concerne ao entendimento dos Tribunais nacionais dos países acima referidos acerca da temática objeto deste trabalho, o documento produzido pela Relatoria Especial para Liberdade de Expressão da CIDH, denominado "Jurisprudencia Nacional en Materia de Libertad de Expresión", do ano de 2016, compila decisões atinentes ao direito à liberdade de expressão.

O documento (CIDH, 2016) classifica as decisões dentro de subcapítulos, referentes a pontos de discussão ou modos de exercício do direito em comento. Neste trabalho serão trazidas à baila decisões atinentes a três temáticas: 1) "Jurisprudencia sobre la Admisibilidad de Limitaciones Impuestas a la Libertad de Expresión: Marco General”; 2) "Jurisprudencia sobre las Condiciones de Admisibilidad de las Limitaciones a la Libertad De Expresión (Estándar de Test Tripartito)” e 3) "Jurisprudencia sobre Libertad de Expresión en Internet". A fim de não delongar o presente trabalho e com o intuito de trazer alguns posicionamentos dos referidos tribunais nacionais sobre a temática, será comentado um julgado de cada país, referente aos grupos acima mencionados. Os julgados dos tribunais selecionados são os que melhor demonstram os pontos de discussão propostos no presente trabalho. 
Em relação ao primeiro ponto, destaca-se a decisão da Corte Suprema de Justiça da Argentina ${ }^{31}$, que julgou, em 2014, o caso "Rodríguez con Google Inc y Yahoo Argentina”. De forma breve, o julgado trata de ação ajuizada por María Belén Rodríguez em face da empresa Google Inc. (sendo posteriormente incluída no polo passivo a empresa Yahoo de Argentina SRL), em razão do uso comercial e não autorizado da imagem da autora, afetando seus direitos de personalidade, já que havia sido vinculada sua imagem a sites de conteúdo pornográfico. Neste caso, a suprema corte argentina analisou o alcance do artigo 13.2 da Convenção Americana, sustentando que:

[...] toda restrição, sanção ou limitação à liberdade de expressão deve ser de interpretação restritiva. [...] Toda censura prévia que sobre ela se exerça padece de forte presunção de inconstitucionalidade, sendo o princípio eventualmente aplicável em caso de abusos de exercício, o da aplicação de responsabilidades ulteriores. Isto se dá porque (...) a jurisprudência do Tribunal tem sido coerente com o princípio orientador segundo o qual o direito de imprensa goza em nosso ordenamento jurídico de uma posição privilegiada. E isso não poderia ser diferente, já que a sociedade contemporânea respira através da informação ${ }^{32}$ ' (ARGENTINA apud CIDH, 2016, p. 25, tradução nossa).

Neste caso, a Corte argentina entendeu pela necessidade de observância dos critérios elaborados pela CIDH para que a limitação à liberdade de expressão seja legítima. 0 excerto da decisão acima colacionado demonstra a posição privilegiada do direito à liberdade de expressão, entendida como fundamental na sociedade contemporânea ${ }^{33}$.

No que concerne ao segundo grupo de decisões, o documento referido contempla, dentre outras, decisão da Suprema Corte de Justiça do Uruguai ${ }^{34}$, na qual se estabeleceu que "ao restringir o gozo de direitos fundamentais, o legislador está limitado 'pela previsão de que a lei restritiva (...) se realize por razões de interesse geral ${ }^{35}$ '” (URUGUAI apud CIDH, 2016, p. 38, tradução nossa). Trata-se, em linhas gerais, de ação de Inconstitucionalidade promovida por Directv de Uruguay Ltda questionando a constitucionalidade de diversos artigos da Lei de serviços de comunicação audiovisual (lei 19.307). 0 argumento da parte autora é de que a lei em comento trouxe, quando da entrada em vigor, 
novos deveres às emissoras, limitando ainda seu direito à liberdade de expressão, já que previa disposições que se dirigiam exclusivamente a ela (URUGUAY, 2016).

O tribunal uruguaio entendeu na mesma linha do proposto pela $\mathrm{CIDH}$, ao reconhecer a necessidade de aplicação do test tripartito antes de limitar o direito à liberdade de expressão, o que pode ser visualizado quando referido que "se a diminuição das possibilidades de fruição ou exercício sofrido pelo direito resulta excessiva em relação com o objetivo proposto, a medida é desproporcional e, consequentemente, ilícita ${ }^{36 "}$ (URUGUAI apud CIDH, 2016, p. 38, tradução nossa).

Por fim, no tocante ao terceiro tópico de decisões, destaca-se jurisprudência oriunda do Superior Tribunal de Justiça do Brasil ${ }^{37}$, publicada em 4 de junho de 2014, na qual, por maioria de votos, os ministros foram favoráveis a tornar sem efeito medida cominatória imposta contra provedor de serviços de busca da internet. Na ocasião, a Ministra Nancy Andrighi sustentou que "a tutela do âmbito virtual exige um 'cuidado redobrado'. Como consequência, 'qualquer tipo de restrição deve ser pensada cuidadosamente' para não afetar 'o perfeito funcionamento' da Rede ${ }^{38 " ~(B R A S I L ~ a p u d ~ C I D H, ~ 2016, ~ p . ~ 91, ~ t r a d u c ̧ a ̃ o ~ n o s s a) . ~}$

No voto da ministra ainda constou a importância dos sites de busca na vida das pessoas, em razão da informação que pode ser acessada a partir daí, o que se coaduna com o entendimento da Comissão Interamericana de que a internet pode servir como ferramenta fundamental nas sociedades democráticas.

Desta forma, constata-se que os tribunais nacionais dos países supra-analisados tendem a decidir as questões atinentes ao objeto deste trabalho de acordo com as diretrizes propostas pela Organização dos Estados Americanos, a partir da concepção de que a Internet é ferramenta capaz de fomentar o exercício do direito à liberdade de expressão. 


\section{CONCLUSÃO}

As análises aqui realizadas demostraram que o direito à liberdade de expressão no contexto latino americano é amplamente protegido, tanto por diplomas internacionais como pelas Constituições internas. Restou evidenciado que este direito contempla diversas facetas e espaços de manifestação, como a Internet.

Verificou-se que no âmbito latino americano, sob a ótica da Organização dos Estados Americanos, o direito à liberdade de expressão é tido como pressuposto das sociedades democráticas, e que a Internet é considerada ferramenta a serviço destas, pois tem a capacidade de ampliar o espaço de debate e de troca de ideias.

Desta forma, a análise dos documentos produzidos pela Organização dos Estados Americanos, através da Comissão Interamericana de Direitos Humanos, demonstrou que o direito à liberdade de expressão é garantia fundamental e que deve ser observada, sendo protegido em todos os campos, mas é reconhecido que, para o pleno exercício deste direito, muito se tem a avançar.

Este avanço pressupõe uma maior inclusão digital, reconhecidas as enormes discrepâncias sociais, econômicas, de gênero, dentre outros, pondo fim ao chamado "fosso digital", assim como a capacitação dos usuários, para que possam fazer uso responsável e autônomo da rede.

A análise ainda demonstrou que a organização estudada entende que eventuais restrições à liberdade de expressão devem ser cautelosamente consideradas, propondo, para tanto, requisitos mínimos que devem ser auferidos a fim de verificar a legitimidade de determinada restrição. Percebeu-se que os recentes períodos de ditadura pelos quais passaram os países latino americanos alimentam as preocupações com violações ao direito à liberdade de expressão, como por exemplo, a censura.

Nas jurisprudências nacionais contidas nos documentos analisados e brevemente tratadas neste trabalho, pode-se perceber que os países tendem a seguir os ditames da Organização, fundamentando suas decisões na Convenção Americana e reconhecendo o potencial da Internet, atentos a necessidade de preservar as características da rede e especialmente 0 princípio da neutralidade. 
Constatou-se, desta forma, que o entendimento expresso pela Organização dos Estados Americanos é de proteção $a b$ initio às manifestações de opinião. As limitações devem ser excepcionais e cumprir determinados requisitos para que possam ser legítimas e, deste modo, se harmonizar aos ditames das sociedades democráticas.

Referente ao exercício deste direito na Internet, o entendimento da Organização é de que as limitações igualmente devem passar pelo crivo dos requisitos, atentando que eventuais restrições neste campo podem trazer implicações ainda maiores, já que o acesso às informações é potencializado, e, desta forma, as restrições tolheriam este direito de forma mais grave.

Por fim, salienta-se que os tempos que correm demandam especial atenção às manifestações de expressão na Internet, uma vez que esta pode ser também utilizada para a propagação de conteúdos que escapam à esfera protetiva, configurando abuso de direito.

\section{NOTAS}

1 De acordo com Leonardi (2012), provedor de conexão, também chamado de provedor de acesso, é uma espécie do gênero provedor de serviço de Internet, podendo ser compreendido como a pessoa jurídica fornecedora de serviços que consistem em possibilitar o acesso de seus consumidores à Internet. Para sua caracterização, basta que a empresa possibilite o acesso de seus clientes à Internet.

2 [...] uma central de reclamação composta por profissionais qualificados para apurar e concluir de forma rápida - desde que logicamente exista notícia de abuso - se o conteúdo tido como ilícito justificaria a remoção [...]. Com isso, eventual decisão do próprio provedor, naquelas circunstâncias, poderia ser questionada no âmbito judicial por eventual usuário que alegasse violação da liberdade de expressão, ou seja, o papel do Poder Judiciário seria exercido de forma residual e em último caso (PODESTA, 2015, p. 396).

3 Conforme Farias (2001, p. 60), Alexander Meiklejohn entende que a liberdade de expressão cumpre duas funções na democracia: uma função informativa, "pela qual o livre fluxo das informações possibilita o melhor conhecimento e a melhor avaliação dos assuntos de relevância pública”, e uma função crítica, através da qual "a liberdade de expressão e comunicação assegura aos cidadãos a faculdade de criticar o poder político, as instituições estabelecidas e os agentes públicos, o que pode resultar na mudança dos governantes".

4 Dentre os principais documentos internacionais, destaca-se a Declaração dos Direitos do Homem e do Cidadão, de 1789, a Declaração Universal dos Direitos Humanos da Assembleia Geral das Nações Unidas, de 1948 e o Pacto Internacional sobre os Direitos Civis e Políticos, que entrou em vigor no Brasil em julho de 1992.

5 Wiener (1948, p. 19; 1984, p. 15) apud Joon Ho Kim (2004, p. 200), "explica que ele e Rosenblueth criaram um termo artificial para designar esse campo de pesquisa porque acreditavam que qualquer terminologia existente traria um viés indesejado ao seu sentido. Assim, eles cunharam o termo cybernetics derivado do grego kubernetes, palavra utilizada para denominar o piloto do barco ou timoneiro, aquele que corrige constantemente o rumo do navio para compensar as influências do vento e do movimento da água. Além do sentido de controle, reforçado pela correspondência que 
kubernetes tem com o latim gubernator, a máquina de leme utilizada em navios seria um dos mais antigos dispositivos a incorporar os princípios estudados pela cibernética."

6 Tecnologias de Informação e Comunicação.

7 Reflexão extraída da obra de Delmas-Marty (2013, p. 92).

8 Do original: "un orden de paz y de justicia, fomentar su solidaridad, robustecer su colaboración y defender su soberanía, su integridad territorial y su independência".

9 Do original: "la promoción y protección de los derechos humanos en el continente americano".

10 A Relatoria Especial é um escritório de caráter permanente, com estrutura operacional própria e com independência funcional, que opera dentro do marco jurídico da CIDH. A Relatoria Especial tem como mandato geral a realização de atividades de proteção e promoção do direito à liberdade de pensamento e de expressão, a partir de determinadas funções (OEA, 2017).

11 Do original: "permite la creación en colaboración y el intercambio de contenidos - es un ámbito donde cualquiera puede ser autor y cualquiera puede publicar".

12 Do original: "transformando el derecho a la libertad de expresión mediante la creación de nuevas capacidades para crear y editar contenidos (a través de fronteras físicas), a menudo sin pasar por el control de la censura, lo que genera nuevas posibilidades para la realización del potencial; nuevas capacidades de organización y movilización (que respaldan en gran medida a otros derechos, como el derecho a la libertad de asociación); y nuevas posibilidades para innovar y generar desarrollo económico (que sustentan a los derechos sociales y económicos)".

13 Do original: "encuentra en Internet um instrumento único para desplegar, incrementalmente, su enorme potencial em amplios sectores da la población".

14 Do original: "Lo que persigue tal principio es que la libertad de acceso y elección de los usuarios de utilizar, enviar, recibir u ofrecer cualquier contenido, aplicación o servicio legal por medio de Internet no esté condicionada, direccionada o restringida, por medio de bloqueo, filtración, o interferencia. Se trata de una condición necesaria para ejercer la libertad de expresión en Internet en los términos del artículo 13 de la Convención Americana [...]"

15 Ao tratar do acesso universal, a Relatoria reconhece as grandes disparidades no acesso às Tecnologias de Informação e Comunicação entre homens e mulheres, bem como a necessidade de inclusão das pessoas com deficiência. Desta forma, entende ser primordial, para falar em acesso universal, promover políticas que possibilitem o acesso aos grupos minoritários e que sofrem de alguma deficiência, tendo como base, neste último caso, a Convenção Interamericana para a Eliminação de todas as Formas de Discriminação contra as Pessoas portadoras de Deficiência (CIDH, 2013b).

16 Do original: "es necesario que se adopten las medidas tendientes a reducir los obstáculos lingüísticos para garantizar que las distintas culturas puedan expresarse y acceder a Internet".

17 Do original: "es condición indispensable para la consolidación, el funcionamiento y la preservación de los regímenes democráticos. La formación de una opinión pública informada y consciente de sus derechos, el control ciudadano sobre la gestión pública y la exigencia de responsabilidad de los funcionários estatales, no sería posible si este derecho no fuera garantizado".

18 Neste sentido, o artigo 11 da Declaração de Direitos do Homem e do Cidadão refere, de modo bem genérico, que o cidadão responderá pelos abusos decorrentes da liberdade de expressão. Já a Declaração Universal dos Direitos Humanos prevê, no artigo XXX, que nenhuma disposição pode ser interpretada de forma a impedir o exercício dos demais direitos previstos, o que demonstra o caráter não absoluto dos direitos ali constantes. Já o Pacto Internacional sobre Direitos Civis e Políticos prevê, no parágrafo 3 do artigo 19, de forma mais ampla, as restrições à liberdade de expressão.

19 Do original: "el ejercicio de la libertad de expresión implica deberes y responsabilidades para quien se expresa. El deber básico que de allí se deriva es el de no violar los derechos de los demás al ejercer esta libertad fundamental".

20 Do original: "(1) la limitación debe haber sido definida en forma precisa y clara a través de una ley formal y material, (2) la limitación debe estar orientada al logro de objetivos imperiosos autorizados por la Convención Americana, y (3) la limitación debe ser necesaria en una sociedad democrática para el logro de los fines imperiosos que se buscan; estrictamente proporcionada a la finalidad perseguida; e idónea para lograr el objetivo imperioso que pretende lograr" 
21 Do original: "una determinada medida restrictiva puede parecer leve si la estudia solamente desde la perspectiva de la persona afectada. Sin embargo, la misma medida puede tener un impacto realmente devastador en el funcionamiento general de Internet y, en consecuencia, en el derecho a la libertad de expresión de todo el conjunto de los usuários".

22 Do original: (1) consagración legal; (2) búsqueda de una finalidad imperativa; (3) necesidad, idoneidad y proporcionalidad de la medida para alcanzar la finalidad perseguida; (4) garantías judiciales; y (5) satisfacción del debido proceso, incluyendo, las notificaciones al usuario".

23 Do original: "la competencia respecto de causas vinculadas con expresiones en Internet debería corresponder exclusivamente a los Estados con los que tales causas presenten los contactos más estrechos, normalmente debido a que el autor reside en ese Estado, la expresión se publicó desde allí o éste se dirige específicamente al público ubicado en el Estado en cuestión. Los particulares solo deberían poder iniciar acciones judiciales en una jurisdicción en la que puedan demostrar haber sufrido un perjuicio sustancial de manera que se prevenga lo que se conoce como 'turismo de la difamación' (forum shopping)".

24 Do original: "la adopción de medidas obligatorias de bloqueo y filtrado de contenidos específicos".

25 A Constitucion de La Nacion Argentina corresponde a Ley nํ⒉430, que fora promulgada no ano de 1853 e reformada, pela última vez, em 1994.

26 Artículo 14.- Todos los habitantes de la Nación gozan de los siguientes derechos conforme a las leyes que reglamenten su ejercicio; a saber: de trabajar y ejercer toda industria lícita; de navegar y comerciar; de peticionar a las autoridades; de entrar, permanecer, transitar y salir del territorio argentino; de publicar sus ideas por la prensa sin censura previa; de usar y disponer de su propiedad; de asociarse con fines útiles; de profesar libremente su culto; de enseñar y aprender.

27 Do original: "Artículo 29.- Es enteramente libre en toda materia la comunicación de pensamientos por palabras, escritos privados o publicados en la prensa, o por cualquier otra forma de divulgación, sin necesidad de previa censura; quedando responsable el autor y, en su caso, el impresor o emisor, con arreglo a la ley por los abusos que cometieren".

28 Do original: "Artículo 22. (Libertad de expresión y derecho a la información).- Toda persona tiene derecho a la libertad de expresión. Este derecho comprende la libertad de buscar, recibir y difundir informaciones e ideas. [...]"

29 Artículo 4o․ Definiciones.- A los efectos de la presente ley se entiende por: A) Base de datos: indistintamente, designan al conjunto organizado de datos personales que sean objeto de tratamiento o procesamiento, electrónico o no, cualquiera que fuere la modalidad de su formación, almacenamiento, organización o acceso. [...]

30 Do original: “Artículo 20. Datos relativos a las telecomunicaciones.- Los operadores que exploten redes públicas o que presten servicios de comunicaciones electrónicas disponibles al público deberán garantizar, en el ejercicio de su actividad, la protección de los datos personales conforme a la presente ley. Asimismo, deberán adoptar las medidas técnicas y de gestiones adecuadas para preservar la seguridad en la explotación de su red o en la prestación de sus servicios, con el fin de garantizar sus niveles de protección de los datos personales que sean exigidos por la normativa de desarrollo de esta ley en esta materia. En caso de que exista un riesgo particular de violación de la seguridad de la red pública de comunicaciones electrónicas, el operador que explote dicha red o preste el servicio de comunicaciones electrónicas informará a los abonados sobre dicho riesgo y sobre las medidas a adoptar. [...]"

31 Corte Suprema de Justicia de la Nación Argentina. Rodríguez María Belén c/google Inc. s/ Daños y Perjuicios. Sentencia de 28 de Octubre de 2014

32 Do original: “'toda restricción, sanción o limitación a la libertad de expresión debe ser de interpretación restrictiv[a]'. [...] '[T]oda censura previa que sobre ella se ejerza padece una fuerte presunción de inconstitucionalidad', siendo el principio eventualmente aplicable en caso de abusos por su ejercicio, el de la aplicación de responsabilidades ulteriores. 'Ello es así ya que (...) la jurisprudencia del Tribunal ha sido consecuente con el principio rector según el cual el derecho de prensa goza en nuestro ordenamiento de una posición privilegiada. Y esto no podría ser de otro modo, puesto que la sociedad contemporánea respira a través de la información[n]'”

33 Outras decisões que tratam desta temática podem ser encontradas no documento referido.

34 Acción de inconstitucionalidad. Sentencia No. 79 de 5 de abril de 2016. 
35 Do original: "al restringir el goce de derechos fundamentales, el legislador está limitado por 'la previsión de que la ley restrictiva (...) se realice por razones de interés general'”.

36 Do original: "si el acortamiento de las posibilidades de goce o ejercicio sufrido por el derecho resulta excesivo en relación con el objetivo propuesto, la medida es desproporcionada y por consiguiente, ilícita".

37 Superior Tribunal de Justiça do Brasil (STJ). Reclamação 5.072. Decisión de 11 de diciembre de 2013, publicada el 4 de junio de 2014.

38 Do original: "la tutela delentorno virtual exige 'un cuidado redoblado'. En consecuencia, '[c] ualquier tipo de restricción debe ser detenidamente pensada' para no afectar 'el perfecto funcionamiento' de la Red".

\section{REFERÊNCIAS}

ALMEIDA, Rafael Luft de. A liberdade de expressão e o discurso de ódio na era da Internet. Revista de Direito das Novas Tecnologias. São Paulo, n. 8, p. 7-32, jul. 2011/jun. 2012.

ARGENTINA. Constitución de la Nacion Argentina (1994). Disponível em: < http://servicios.infoleg.gob.ar/infolegInternet/anexos/0-4999/804/norma. htm>. Acesso em: 10 jun. 2017.

. Parlamento. Lei 26.032, de 16 de junho de 2005. Disponível em: <http:// servicios.infoleg.gob.ar/infolegInternet/anexos/105000-109999/107145/ norma.htm=>. Acesso em 10 jun. 2017.

Corte Suprema de Justicia de la Nación Argentina. Rodríguez María Belén c/google Inc. s/ Daños y Perjuicios. Sentencia de 28 de Octubre de 2014. Disponível em: <http://sjconsulta.csjn.gov.ar/sjconsulta/documentos/ verDocumentoById.html?idDocumento=7162581 >. Acesso em: 01 ago. 2017.

ASSANGE, Julian. Cypherpunks. 1. Ed. São Paulo: Boitempo, 2013.

BARROSO, Luís Roberto. Liberdade de expressão versus direitos da personalidade. Colisão de direitos fundamentais e critérios de ponderação. In: SARLET, Ingo Wolfgang (org.). Direitos fundamentais, informática e comunicação: algumas aproximações. Porto Alegre: Livraria do Advogado, 2007, p. 63-100.

. Decreto no. 678, de 6 de novembro de 1992. Convenção Americana sobre Direitos Humanos (Pacto de São José da Costa Rica), de 22 de novembro de 1969. Disponível em: <http://www.planalto.gov.br/ccivil_03/decreto/d0678. htm>. Acesso em: 17 jun. 2017. 
Constituição (1988). Constituição da República Federativa do Brasil: promulgada em 5 out. 1998. Disponível em: <http://www.planalto.gov.br/ ccivil_03/constituicao/constituicaocompilado.htm> Acesso em: 15 abr. 2017.

Lei no 12.965, de 23 de abril de 2014. Estabelece princípios, garantias direitos e deveres para o uso da Internet no Brasil. Diário Oficial, Brasília, DF. Disponível em: < http://www.planalto.gov.br/ccivil_03/_ato2011-2014/2014/ lei/l12965.htm>. Acesso em: 15 abr. 2017.

. Lei no 13.188, de 11 de novembro de 2015. Dispõe sobre o direito de resposta ou retificação do ofendido em matéria divulgada, publicada ou transmitida por veículo de comunicação social. Diário Oficial, Brasília, DF. Disponível em: <http://www.planalto.gov.br/CCIVIL_03/_Ato2015-2018/2015/ Lei/L13188.htm>. Acesso em: 20 abr. 2017.

. Superior Tribunal de Justiça. Acórdão. Recurso Especial №. 1568935 / RJ. Terceira Turma. Relator: Ricardo Villas Bôas Cueva. Julgado em 05/04/2016. Disponível em: <https://ww2.stj.jus.br/processo/revista/inteiroteor/?num_ registro $=201501011370 \& d t \_p u b l i c a c a o=13 / 04 / 2016>$. Acesso em: 17 abr. 2017.

CIDH. Marco Jurídico Interamericano sobre el Derecho a la Libertad de Expresión, 2010. Relatoría Especial para la Libertad de Expresión. ISBN 978-08270-5457-8, 2010. Disponível em: <http://www.oas.org/es/cidh/expresion/ docs/publicaciones/MARCO\%20JURIDICO\%20INTERAMERICANO $\% 20$ DEL\%20DERECHO\%20A\%20LA\%20LIBERTAD\%20DE\%20EXPRESION\%20 ESP\%20FINAL\%20portada.doc.pdf>. Acesso em: 25 jun. 2017.

Informe anual de la Relatoría Especial para la Libertad de Expresión, 2013a: Informe anual de la Comisión Interamericana de Derechos Humanos, 2013, vol.2 / Catalina Botero Marino, Relatora Especial para la Libertad de Expresión, 2013. Disponível em: <http://www.oas.org/es/cidh/expresion/ docs/informes/anuales/2014_04_22_IA_2013_ESP_FINAL_WEB.pdf>. Acesso em: 25 Jun. 2017.

Libertad de expresión e internet, 2013b. Relatoría Especial para la Libertad de Expresión. Comisión Interamericana de Derechos Humanos. OEA/ Ser.L/V/II CIDH/RELE/INF.11/13, 2013. Disponível em: <http://www.oas.org/ 
es/cidh/expresion/docs/informes/2014_04_08_Internet_WEB.pdf>. Acesso em: 25 Jun. 2017.

Jurisprudencia Nacional en Materia de Libertad de Expresión. Relatoría Especial para la Libertad de Expresión de la Comisión Interamericana de Derechos Humanos. Edison Lanza, Relator Especial para la Libertad de Expresión, 2016. Disponível em: < http://www.oas.org/es/cidh/expresion/ docs/basicos/JURISPRUDENCIA_ESP.pdf>.Acesso em: 25 Jun. 2017.

Estándares para una Internet libre, abierta e incluyente, 2017. / Relatoría Especial para la Libertad de Expresión de la Comisión Interamericana de Derechos Humanos. v.; cm. (OAS. Documentos oficiales ; OEA/Ser.L). ISBN 9780-8270-6636-6, 2017. Disponível em: <http://www.oas.org/es/cidh/expresion/ docs/publicaciones/INTERNET_2016_ESP.pdf>. Acesso em: 25 Jun. 2017.

CLARÍN. Libertad de expresión: Macri firmó la declaración de Chapultepec. Disponível em: <https://www.clarin.com/politica/libertad-expresion-macrideclaracion- chapultepec_0_SJHGW2Ad.html>. Acesso em 10 jun. 2017.

DELMAS-MARTY, Mireille. Résister, responsabiliser, anticiper. Paris: Seuil, 2013.

FARIAS, Edilsom Pereira de. Liberdade de expressão e comunicação: teoria e proteção constitucional. 2001. Tese, Doutorado em Direito, Universidade Federal de Santa Catarina, Florianópolis, 2001.

KIM, Joon Ho. Cibernética, ciborgues e ciberespaço: notas sobre as origens da cibernética e sua reinvenção cultural. In: Horizontes Antropológicos, Porto Alegre, ano 10, n. 21, p. 199-219, jan./jun. 2004.

LEONARDI, Marcel. Internet: elementos fundamentais. In: Responsabilidade Civil na Internet e nos demais meios de comunicação, coordenado por Regina Beatriz Tavares da Silva e Manoel J. Pereira dos Santos. 2. ed. São Paulo: Saraiva, 2012.

MEYER-PFLUG, Samantha Ribeiro; LEITE, Flávia Piva. Liberdade de expressão e o direito à privacidade no Marco Civil da Internet. In: DE LUCCA, Newton; SIMÃO FILHO, Adalberto; LIMA, Cíntia Rosa Pereira. Direito e Internet III: Marco Civil da Internet III - tomo I. São Paulo : Quartier Latin, 2015. 
MEYER-PFLUG, Samantha Ribeiro. Liberdade de expressão e discurso do ódio. São Paulo: Revista dos Tribunais, 2009.

ORGANIZAÇÃO DOS ESTADOS AMERICANOS. Carta de la organización de los Estados Americanos. Bogotá, Colômbia, 1948. Disponível em: <http://www.oas. org/es/sla/ddi/docs/tratados_multilaterales_interamericanos_A-41_carta_OEA. pdf>. Acesso em: 14 jun. 2017.

. Quem somos. Sítio Oficial OEA. 2017. Disponível em: <http://www.oas. org/pt/sobre/quem_somos.asp>. Acesso em: 16 jun. 2017.

PODESTA, Fábio Henrique. Marco Civil da Internet e Direitos de Personalidade. In: DE LUCCA, Newton; SIMÃO FILHO, Adalberto; LIMA, Cíntia Rosa Pereira. Direito e Internet III: Marco Civil da Internet III - tomo I. São Paulo: Quartier Latin, 2015.

SALDANHA, Jânia Maria Lopes. Os desafios do "império cibernético" na era da aceleração da informação: um "sexto continente" de liberdade perfeita ou de controle perfeito? In: Direitos emergentes na sociedade global: anuário do programa de pós graduação em direito da UFSM. Ijuí: Editora Unijuí, 2013.

SOUZA, Carlos Affonso Pereira de. As cinco faces da proteção à liberdade de expressão no marco civil da internet. In: DE LUCCA, Newton; SIMÃO FILHO, Adalberto; LIMA, Cíntia Rosa Pereira. Direito e Internet III: Marco Civil da Internet - tomo II. São Paulo: Quartier Latin, 2015.

URUGUAY. Constitución de la República (1967). Disponível em: <https:// parlamento.gub.uy/documentosyleyes/constitucion>. Acesso em: 10 jun. 2017.

. Parlamento. Lei 18.331, de 06 de agosto de 2008. Disponível em: < https://parlamento.gub.uy/documentosyleyes/leyes?Ly_Nro=18331\&Ly_fech aDePromulgacion\%5Bmin\%5D\%5Bdate\%5D=\&Ly_fechaDePromulgacion $\% 5$ Bmax\%5D\%5Bdate\%5D=\&Ltemas=\&tipoBusqueda=T\&Searchtext=>. Acesso em: 10 jun. 2017.

Parlamento. Lei 19.307, de 22 de dezembro de 2014. Disponível em: $<$ https://parlamento.gub.uy/documentosyleyes/leyes?Ly_Nro=19307\&Ly_fec haDePromulgacion\%5Bmin\%5D\%5Bdate\%5D=\&Ly_fechaDePromulgacion\% 
5Bmax $\% 5 \mathrm{D} \% 5 \mathrm{Bdate} \% 5 \mathrm{D}=\&$ Ltemas=\&tipoBusqueda=T\&Searchtext=>. Acesso em: 10 jun. 2017.

. Suprema Corte de Justicia de Uruguay. IUE 1-18/2015. Directv de Uruguay Limitada c/ Poder Legislativo. Acción de inconstitucionalidad. Sentencia No. 79 de 5 de abril de 2016. Disponível em: <http://www.poderjudicial. gub.uy/images/resoluciones/2016/sent_scj_05-04-16_inconstituc_ley_de_ medios_19307.pdf> . Acesso em: 01 ago. 2017.

Recebido em: 16-10-2017

Aprovado em: 11-07-2019

\section{Rosane Leal da Silva}

Doutora pela Universidade Federal de Santa Catarina (UFSC), na área de concentração Direito, Estado e Sociedade, com pesquisa sobre criança e adolescente na sociedade informacional. Mestre em Integração Latino-Americana pela Universidade Federal de Santa Maria (UFSM). Professora associada da Universidade Federal de Santa Maria, nos cursos de Graduação e Mestrado em Direito. Líder do Grupo de Pesquisa Teoria Jurídica no Novo Milênio (UFN) e do Grupo de Pesquisa Núcleo de Direito Informacional (UFSM). Integrante do Núcleo de Estudos Jurídicos e Sociais da Criança e do Adolescente - NEJUSCA - da Universidade Federal de Santa Catarina. Coordena o Núcleo de Direito Informacional, na Universidade Federal de Santa Maria.

E-mail: rolealdasilva@gmail.com

\section{Bárbara Eleonora Taschetto Bolzan}

Mestre em Direito no Programa de Pós-Graduação da Universidade Federal de Santa Maria (UFSM), na área de Concentração: Direitos Emergentes na Sociedade Global e linha de Pesquisa: Direitos na Sociedade em Rede. Especialista em Direito Médico e da Saúde, pela Universidade Luterana do Brasil (ULBRA). Integrante do Observatório Permanente de Discurso de Ódio na Internet da Universidade

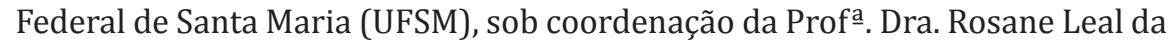
Silva. Advogada.

E-mail: barbaratbolzan@hotmail.com 


\section{Paula Fabíola Cigana}

Mestranda pelo Programa de Pós-graduação em Direito da Universidade Federal de Santa Maria (UFSM). Especialista em Direito e Advocacia Empresarial pela Universidade Anhanguera - (UNIDERP). Especialista em Direito Processual Civil pelo Centro Universitário Internacional - UNINTER. Tabeliã e Registradora no Estado do Rio Grande do Sul.

E-mail: paulafcigana@hotmail.com

Universidade Federal de Santa Maria - UFSM. Programa de Pós-Graduação em Direito. PPGD - Campus Santa Maria. Av. Roraima, 1000 - Camobi, Santa Maria - RS, 97105-900. 